\title{
Solvent for Solution for Infusion Dosage Form
}

National Cancer Institute

\section{Source}

National Cancer Institute. Solvent for Solution for Infusion Dosage Form. NCI Thesaurus.

Code C149938.

Liquid sterile preparation consisting of a solvent containing no active substances,

intended for use in the preparation of a solution for infusion. 